\title{
IMPLEMENTASI SIA PADA INSTANSI PEMERINTAH DI SUMATERA SELATAN
}

\author{
Maidiana Astuti ${ }^{1)}$ \\ email: maidianadualima@gmail.com \\ 1) Manajemen, Universitas Teknokrat Indonesia
}

\begin{abstract}
Abstrak
Penelitian ini bertujuan untuk mengetahui implementasi SIA pada instansi pemerintah di Sumatera Selatan. Penelitian ini menggunakan data primer yang diperoleh langsung dari obyek yang diteliti. Hasil penelitian ini adalah dukungan pimpinan berpengaruh positif dan signifikan terhadap SIA, pengalaman pengguna berpengaruh negatif dan tidak signifikan terhadap SIA, pelatihan pengguna system berpengaruh positif dan signifikan terhadap SIA.
\end{abstract}

Kata kunci: dukungan pimpinan, pengalaman pengguna, pelatihan system, SIA.

\section{Pendahuluan}

\subsection{Latar Belakang}

Peningkatan penggunaan sistem informasi akuntansi membawa beberapa perubahan dalam aliran pekerjaan, baik pada sektor swasta maupun sektor publik.

Penelitian-penelitian tersebut sebagian besar dilakukan terhadap keberhasilan sistem informasi disektor swasta dan masih sedikit penelitian yang dilakukan pada organisasi pemerintah, dimana pemerintah termasuk dalam domain sektor publik. Sistem informasi akuntansi yang biasa digunakan pada sektor swasta adalah sistem informasi akuntansi berbasis akrual sedangkan sistem informasi akuntansi yang digunakan pada sektor publik lebih banyak menggunakan sistem akuntansi berbasis kas (Mardiasmo, 2002).

Disamping itu berdasarkan hasil pemeriksaan Badan Pemeriksa Keuangan (BPK) atas Laporan Keuangan Pemerintah Pusat (LKPP) diketahui bahwa opini atas LKPP adalah "tidak menyatakan pendapat (disclaimer). BPK menyatakan masih terdapat kelemahankelemahan signifikan dalam desain dan implementasi pengendalian intern yang ditemukan pada setiap entitas yang meliputi : (1) pelaksanaan Sistem Akuntansi Pemerintah Pusat (SAPP) belum memadai, (2) prosedur pembukuan dan penyusunan Laporan Keuangan dan LRA belum dilakukan sesuai dengan Sistem Akuntansi dan Pelaporan Keuangan Pemerintah Pusat, (3) personil yang memiliki kemampuan baik bidang akuntansi keuangan maupun aset masih terbatas, (4) rekonsiliasi dan verifikasi baik pendapatan maupun belanja pelaksanaannya belum sebagai mestinya, dan (5) LRA kementerian negara/lembaga sebagian besar belum diperiksa oleh unit pengawas intern kementerian negara/lembaga yang bersangkutan (BPK, 2007).

Penelitian yang dilakukan oleh Sabherval (2003) diperoleh kesimpulan bahwa keterkaitan antara empat konstruksi yang mewakili keberhasilan sistem informasi akuntansi adalah a) kepuasan pengguna b). menggunakan sistem c). kegunaan yang dirasa dan d) kualitas sistem. Berbeda dengan hasil penelitian terdahulu yang telah dilakukan oleh Choe, (1996) dimana diperoleh kesimpulan bahwa sistem informasi akuntansi yang berkualitas harus memiliki ciri-ciri a). Akurat, mencerminkan keadaan yang sebenarnya. b). Tepat Waktu, informasi itu harus tersedia atau ada pada saat informasi tersebut diperlukan, tidak besok atau beberapa jam lagi. c). Relevan, informasi yang diberikan harus sesuai dengan yang dibutuhkan dan d). Lengkap, informasi harus diberikan secara lengkap. 


\subsection{Masalah}

Berdasarkan uraian mengenai latar belakang, maka permasalahan penelitian ini adalah bagaimana implementasi SIA pada instansi pemerintah di Sumatera Selatan.

\subsection{Tujuan}

Berdasarkan uraian mengenai permasalahan, maka tujuan dari penelitian ini adalah:

Untuk menganalisis implementasi SIA pada instansi pemerintah di Sumatera Selatan.

\section{Pembahasan}

Salah satu faktor pendukung kualitas laporan keuangan adalah sistem informasi akuntansi, dimana laporan keuangan dihasilkan dari suatu proses yang didasarkan pada input yang baik, proses yang baik dan output yang baik. Ketiga aspek tersebut haruslah terpadu dan berkesinambungan sebagai pondasi sistem pelaporan keuangan yang baik. (Cheney, Mann, et all, 1986).Sistem informasi akuntansi merupakan suatu komponen atau sub sistem dari suatu organisasi yang mempunyai tanggung jawab atas penyiapan informasi keuangan guna membantu manajemen dalam pembuatan keputusan. Setiap manajemen dalam sebuah organisasi memerlukan informasi yang berbeda sesuai dengan tanggung jawab dan wewenang yang dimilikinya. Semakin rendah tingkat manajemen memerlukan informasi yang rinci mengenai operasi dan kegiatan yang akan dilakukan, semakin tinggi tingkat manajemen membutuhkan informasi yang lebih ringkas.

Penelitian dilakukan pada instansi pemerintah pusat yaitu kantor wilayah departemen/lembaga pemerintah non departemen pada tingkat propinsi. Data yang digunakan dalam penelitan ini adalah data primer yang diperoleh langsung dari obyek yang diteliti dengan mengirimkan kuesioner serta dengan melakukan wawancara secara langsung. Dalam penelitian ini populasi adalah pegawai yang ada pada unit akuntansi pada setiap Satker yang terdiri dari minimal empat orang sehingga seluruh populasi menjadi 100 orang.
Model regresi yang diajukan adalah :

$$
\begin{aligned}
& Y_{\text {keberhasilan SIA }}=\alpha+\beta_{1} \text { supp }+\beta_{2} \exp +\beta_{3} \text { train } \\
& +\varepsilon \\
& \text { dimana : } \\
& Y_{\text {keberhasilan SIA }} \quad \text { : } \quad \text { Keberhasilan } \\
& \text { sistem } \\
& \text { akuntansi. }
\end{aligned}
$$

Hasil uji validitas atas variabel dukungan pimpinan diketahui bahwa pertanyaan yang diajukan pada responden memiliki nilai $r$ hitung yang lebih besar dari $r$ tabel sehingga memiliki nilai internal consistency yang positif. Dengan demikian pertanyaan yang diberikan kepada responden dinyatakan valid.

Pengujian reliabilitas dilakukan dengan menggunakan teknik Split Half. Nilainilai untuk pengujian reliabilitas berasal dari skor-skor item angket yang valid. Item yang tidak valid tidak dimasukkan dalam pengujian ini. Dari hasil pengujian reliabilitas diketahui bahwa masing-masing item pertanyaan yang diajukan kepada responden semuanya reliabel.

Variabel dukungan pimpinan, pelatihan pengguna, pengetahuan teknologi informasi memiliki nilai Kolmogorov hitung yang lebih kecil dari nilai Kolmogorov tabel sehingga data yang diperoleh terdistribusi secara normal.

Keberhasilan sistem informasi akuntansi diukur dari kepuasan pengguna. Kisaran jawaban responden yang terendah yaitu 39 dan tertinggi yaitu 80 . Dengan nilai rata-rata sebesar 65,4, maka jawaban responden terhadap keberhasilan sistem informasi akuntansi ini menunjukkan kecenderungan kepuasan penggunaan sistem informasi akuntansi. 
Variabel kedua yaitu dukungan pimpinan (supp) yang ditunjukkan dari keterlibatan, perhatian dan harapan yang tinggi terhadap sistem informasi akuntansi. Dari jawaban responden diketahui bahwa nilai terendah adalah 11 dan nilai jawaban tertinggi adalah 40 sementara nilai rata-ratanya adalah 31,5. Hal ini mengindikasikan bahwa rata-rata responden memiliki setuju bahwa pimpinan memiliki sikap yang sangat setuju terhadap keberhasilan sistem informasi akuntansi.

Pengalaman pengguna sistem diukur dengan skala rasio dengan batas maksimal 10 tahun. Karena data yang terkumpul dari responden menunjukkan abnormalitas maka terhadap variabel ini dilakukan perhitungan ulang dengan menggunakan log. Hasil perhitungan ini menghasilkan nilai terkecil 0 dan nilai terbesar 2,30 dimana nilai rataratanya sebesar 1,27. Nilai ini mengindikasikan bahwa sebagian besar responden memiliki rata-rata pengalaman dibidang sistem informasi akuntansi.

Hasil analisis dengan model regresi linear variabel independen terhadap variabel dependen menghasilkan nilai persamaan di bawah ini.

$$
\begin{array}{lrrrr}
\mathrm{Y}_{\text {Sccs }}=21,312 & +1,334 \text { sup } & 2,430 \mathrm{exp}+ \\
1,026 \mathrm{tr} & \mathrm{Se} & = & 0,169 & 1,351 \\
0,315 & \mathrm{Se} & & & \\
3,255 & \mathrm{t}_{\text {hit }} & & 7,916 & 1,799
\end{array}
$$$$
\text { Fhit }=
$$$$
1,793
$$$$
15,649 \quad \mathrm{df}=75 \quad \mathrm{DW}=
$$

Dilihat dari hasil regresi, koefisien $\left(\mathrm{R}^{2}\right)$ adalah sebesar 0,556, hal ini menunjukan bahwa variabel-variabel yang dimasukan dalam model mampu menjelaskan variasi variabel dependen $\left(\mathrm{Y}_{\mathrm{Sccs}}\right)$ sebesar 55,6 persen sedangkan sebesar 44,4 persen di jelaskan oleh variabel lain yang tidak dimasukan dalam model.

Nilai $\mathrm{F}$ hitung $=15,649$ pada tingkat kepercayaan 95 persen lebih besar dibandingkan dengan $\mathrm{F}_{0,05}$ tabel (5:80) sebesar 2,33, hal ini menunjukkan signifikansi hasil regresi, disamping itu hasil regresi juga menunjukkan signifikansi pada tingkat kepercayaan 99 persen dimana $\mathrm{F}_{0,01}$ tabel (5:80) adalah sebesar 3,25. Kesimpulan statistik menyatakan bahwa hasil pengujian berpengaruh sangat nyata. Dengan demikian keberhasilan sistem informasi akuntansi instansi $\left(\mathrm{Y}_{\text {Sccs }}\right)$ sebagai variabel dependen secara simultan dipengaruhi secara nyata oleh variabel dukungan pimpinan $\left(\beta_{1} s p\right)$, pengalaman pengguna sistem $\left(\beta_{2} \exp \right)$, pelatihan $\left(\beta_{3}\right.$ tr $)$ sebagai variabel independen.

\section{KETERBATASAN PENELITIAN}

Penelitian ini memiliki keterbatasan, yang memerlukan perbaikan ataupun elaborasi untuk penelitian yang lebih baik. Adapun keterbatasan penelitian ini adalah :
a. Pemilihan subjek penelitian di kantor pemerintahan yang terikat pada peraturan dan kebijakan pemerintah.
b. Penelitian hanya mengevaluasi penerapan beberapa variabel sistem informasi akuntansi dalam instansi pemerintah.
c. Masih perlu diteliti lebih lanjut karena belum banyak yang melakukan penelitian tentang sistem informasi akuntansi di instansi pemerintahan.

\section{Kesimpulan}

Berdasarkan hasil penelitian, didapatkan bahwa:

1. Dukungan pimpinan berpengaruh positif dan signifikan terhadap Sistem Informasi Akuntansi pada instansi pemerintah di Sumatera Selatan.

2. Pengalaman pengguna berpengaruh negatif dan tidak signifikan terhadap Sistem Informasi Akuntansi pada instansi pemerintah di Sumatera Selatan.

3. Pelatihan pengguna system berpengaruh positif dan signifikan terhadap Sistem Informasi Akuntansi pada instansi pemerintah di Sumatera Selatan. 


\section{Daftar Pustaka}

Ajzen, I., \& Fishbein, M. (1980). Understanding attitudes and predicting social behavior, Englewood Cliffs, NJ: Prentice-Hall.

Ang CL., Davies MA., Finlay PN., 2001, An Empirical Model of IT Usage in the Malaysian Public Sector, Journal of Strategic Information Systems, 10.

Bailey, James E., \& Sammy W Pearson. 1983. Development Of A Tool For Measuring And Analyzing Computer User Satisfaction. Management Science. Vol 29. No. 5. Pg 530.

Barry E Cushing, Romney Martha1 D, 2003. Accounting Information System. John. Adison Wishley.

Bodnar H George William S. Hopwood. 2007. Accounting Information System..Edisi 9.Terjemahan. Penerbit Andi. Cheney, P.H., Mann, R.I. dan Amoroso, D.L., 1986, Organization Factors Affecting the Success of end User Computing, Journal of Management Information Systes, 3.

Cheney, P.H., Mann, R.I. dan Amoroso, D.L., 1986, Organization Factors Affecting the Success of end User Computing, Journal of Management Information Systes, 3.

Delone, W.H., 1988, Determinants of Success for Computer Usage in Small Businss, MIS Quarterly, 12.

Ein dor, P dan Segev, E., 1978, Organizational Context and The Success of Management Information Systems, Management Science, 24.

Ferdinand A., 2006, Metode Penelitian Manajemen, Badan Penerbit Universitas Diponegoro.

Gujarati, D.N., (2003), Basic Econometrics, 4th Edition, McGraw-Hill International Editions, Singapore.
Hirschheim RA., Assessing Participative Systems Design : Some Conclusion from an Exploratory Study, Information and Management, 6 .

Hussein, R, Selamat, MH, Anom, RB, Karim, NSA, Mamat, (2003), The Impact of Organizational Factors on Information Systems Success : An Empirical Investigation on the Malaysian Electronic-Government Agencies,

Ives, B., Hamilton, S. and Olson, MH., 1984, User Involvement and MIS Success : A Review of Research Management Science, 30.

Kanungo, S., Sadarvati, S., Srinivas, Y., 2001, Relating It Strategy and Organizational Culture : An Empirical Study of Public Sector Units in India, Department of Management Studies Indian Istitute of Technology Hauz Kas, India.

Min Coe, Jong, 1996, The Relationship among Performance of Accounting Information Systems, Influence Factors and Evolution Level of Information Systems, Journal of Management Information Systems.

Montazemi, A.R., 1988, Factors Affecting Information Satisfaction in the Context of the Small Business Environment, MIS Quarterly, 12

Nolan, RL., 1973, Managing the Computer Resource : A Stage Hypotheis, Communications of the ACM.

Olson, MH, and Ives, B., 1981, Users Involvement in Systems Design : An Empirical Test of Alternative Approaches, Information and Management.

Rajiv S., Anand J., Charles C., 2004, Information Systems Success: Dimensions and Determinants, University of Missouri

Rainer, R Kelly., \& Hugh J Watson. 1995. The Keys To Executive Information System Success. Journal of Management 
Information System. ABI?INFROM Research. Vol 12, 2. Pg 83.

Sabherwal, D., Jerayaj, A., Chowa, C., 2006, Information Systems Success: Individual and Organizational Determinants, Management Science, 52, 1849

Sanders, G.L. dan Courtney, J.F., 1985, A Field Study of Organizational Factors Influencing DSS Success, MIS Quarterly, 9

Santoso, S., 2001, Statistik Non Parametrik, Elex Media Komputindo, Jakarta.

Tait, P. dan Vessey, I., 1988, The Effect of User Involvement on Systems Success : A Contingency Approach, MIS Quartely, 12.

Vroom, V. (1964), Work and motivation, 1st ed. United States. Wiley and Sons Inc.

Yaberbaum GJ., and Nosek, 1992, Effect of Information Sistem Education and Training on User Satisfaction, Information and Management, 22

Yap, CS, 1990, Distinguishing Characteristics of Organizations using Computers, Information and Management.

Xu, Hongjiang. 2003. Critical Success Factor For Accounting Information System Data Quality. University Of Southern Queensland. Australia.

Zmud RW., 1979, Individual Differences and MIS Success, Management Science.

, Peraturan Menteri Keuangan Nomor 171/PMK.06/2007 tentang Sistem Akuntansi dan Pelaporan Keuangan Pemerintah Pusat, Departemen Keuangan Republik Indonesia, 2007. 